\title{
Early Childhood Development (0 - 6 Years 0ld) from Healthy to Pathologic: A Review of the Literature
}

\author{
Chkirate Meriem', Mammad Khaoula1, Chtabou Ghizlane1, \\ Mdaghri Alaoui Asmaa ${ }^{2,3}$, Ahami 0. T. Ahmed1 \\ ${ }^{1}$ Clinical Neuroscience and Applied Nutrition Unit, Department of Biology, Faculty of Sciences, Kenitra, Morocco \\ ${ }^{2}$ Pediatric Service 2, Children's Hospital, University Hospital Center (UHC), Ibn Sina, Rabat, Morocco \\ ${ }^{3}$ Research Team in Congenital Anomalies, Faculty of Medicine and Pharmacy, Mohammed V University, Rabat, Morocco \\ Email: khaoula.mammad@gmail.com
}

How to cite this paper: Meriem, C., Khaoula, M., Ghizlane, C., Asmaa, M.A. and Ahmed, A.O.T. (2020) Early Childhood Development (0 - 6 Years Old) from Healthy to Pathologic: A Review of the Literature. Open Journal of Medical Psychology, 9, 100-122.

https://doi.org/10.4236/ojmp.2020.93009

Received: April 22, 2020

Accepted: May 30, 2020

Published: June 2, 2020

Copyright () 2020 by author(s) and Scientific Research Publishing Inc. This work is licensed under the Creative Commons Attribution International License (CC BY 4.0).

http://creativecommons.org/licenses/by/4.0/

\section{(c) (i) Open Access}

\begin{abstract}
Early childhood development involves an appropriate global intervention concerning the different areas of development such as: physical, cognitive, language and socio-emotional [1]. Especially during the first six years of life in an adequate environment rich in exchange and interaction. We will present in this article a review of the literature concerning normal early childhood development, focus firstly in normal development's steps, the importance of first experiences and first aid with a stable and caring attachment figure. second, we will describe the various developmental disorders, occurring during this age group which extends from birth to 6 years and based on the DSM5 classification, namely that developmental delay may concern only one aspect of development (e.g. language delay or motor delay specifically) or concern the different aspects of development (overall development delay). The dynamics of development is also important to clarify because schematically we contrast the pathologies fixed to progressive pathologies (where we find the concepts of stagnation or regression in the development of the child). We will discuss in the third chapter, the interest of early detection as well as the multiple clinical and psychometric diagnostic tools, which aim to detect any delay or disorder in order to initiate appropriate care and minimize the long-term consequences.
\end{abstract}

\section{Keywords}

Early Childhood, Normal Development, Developmental Disorder, Early Screening, Remediation 


\section{Introduction}

The development of the child implies a dynamic, an evolution, and all of the successive processes which, in a determined order, lead an organism to maturity [2]. This continuous process follows the same sequence in all children and is closely linked to the maturation of the nervous system. Also, it is considered to be the result of various environmental internal genetic forces, epigenetic depending both on the characteristics that the child has at birth (innate) and on the contribution of acquired experiences.

Each year, more than 200 million children under the age of five fail to reach their full development potential due to their exposure to multiple problems, including poverty, malnutrition, poor health and an unstimulating family environment, which slow down their physical, cognitive, language and socio-emotional development [1] [3] [4].

Early childhood development is indeed a concept from neuroscience and behavioral research. This concept, established over the decades, has gradually highlighted the importance of the first years of life, which shape the entire life of the child. Thus, his early experiences lay the foundations of neural architecture and are decisive for the robustness or weakness of his learning abilities, his health and the behavior he will adopt throughout his life [1] [5].

And more than any other human being, the child is born with a significant discrepancy in maturation between a rapidly functioning sensory system and a sensitive system, on the other hand, a very immature motor nervous system. It will be thus, subject to an influx of stimuli and sensations with few possibilities of motor responses.

This situation promotes intense dependence on adults, while his remarkable cerebral capacities allow him to gather a large amount of information and to develop a self-awareness and a language which both increase the importance information provided by the entourage and very early on favor the ability to differentiate themselves from those around them and to oppose them [6].

Early childhood development is a crucial phase of human development. No other period of life will carry out such an extensive transformation in such a short period of time, leading to the constitution of a human, sociable being, endowed from the age of two to three, with many already mature functions and all developmental delay during this period of early childhood, have consequences on mental physical health, on behavior and learning, in the long term. Numerous researches today show that specific signs of psychopathology can be identified very early in the development of the child [7]. It also seems that certain childhood disorders are good predictors of disorders in adulthood [8].

An in-depth study of early childhood development is thus essential, in order to meet the challenge for physical, mental and moral well-being of early childhood and, given the necessary means of prevention, early detection of disorders and adequate care for a good subsequent development of the child.

This article will attempt to carry out a review of the scientific literature concern- 
ing healthy development in early childhood and to cite the various developmental disorders occurring during this age group which extends from birth to 6 years.

So the first chapter will focus on normal development, then the second, on pathological development, the third on early detection and the last chapter on adequate management.

\section{Early Childhood Development}

Among all known species, the little of the human remains the longest helpless and not at all prepared to face the outside world. Likewise, preparing a child to become an active member in the society in which he lives requires support and interest from parents (caregivers, affection and interaction), the family, educators, healthcare professionals, with a view to good overall development, both physical and psychological. The work of some psychologists such as [9] [10] shows that "by the time we realize that the child is experiencing certain difficulties or academic failure, this last has already lost almost everything".

The period of early childhood is considered to be the most important developmental phase of life and requires a multidimensional and regular evaluation according to the chronological age of the child. It is during this dynamic phase and of increasing vulnerability that various changes take place, as well, on the physical, mental as mental level and where different stages succeed meeting obstacles, more or less difficult to face and overcome to develop.

The quality of the different stimuli, namely: the first links, early interactions, the parent/child psycho-affective relationship, the family, the effect of external stimuli: experiences and environmental conditions, profoundly affected development at adulthood.

Early childhood is therefore a crucial and sensitive period marked by the most rapid development, particularly with regard to the central nervous system and during which, thought, feeling and socialization reach increasing levels of complexity, the child gradually adopts a behavior favorable to learning, experiences, exploration of the outside world by means of the senses: the child grasps, explores, experiences learns to master movement and, as a result, creates, establishes and consolidates links and pathways in the brain that will be decisive for the proper development of brain function.

According to the international political standards, WHO defines early childhood as the period from prenatal development to the age of eight [11]. The dictionary of the French language of Emile [12], determine the early childhood as a period from 0 to 6 years, studies the first phenomena of physical, intellectual and moral life in small children and embracing only the first three or four years, second childhood: the period around 6 years to 12 years is that which designates the normal period of education and instruction.

\section{Development Stages}

During his development, the child goes through several stages, according to 
WHO [13], the mother must be in good physical and emotional health before and during pregnancy for the foetus to develop optimally. By definition "Optimal development of the fetus" is his state at birth which offers the newborn the greatest chance of surviving and thriving during the neonatal period and early childhood and which predisposes it so that its initial development does not have no harmful consequences later in its existence.

\subsection{Prenatal Period}

From conception to birth, the child already has a singularity and a history. This prenatal period is characterized by 2 processes:

The rapid growth of the fetus and the maturation of organs and tissues and its development which essentially depends, during the first trimester, the initial phase of gestation, on genetic factors.

At the end of the first trimester, all the organs are formed and functional, the fetus gets to know him and his universe and will acquire sensitive and sensory skills allowing him to perceive, act and interact in his environment while keeping in mind the intrauterine experiences. Later, during the second third trimester, the factors linked to the environment and to the hormonal state become preponderant.

The brain during fetal life is still in full development. The underlying mechanisms are multiple (neurogenic, gliogenic, migration, neuronal differentiation and apoptosis, synaptic, dendritic and axonal growth, proliferation and elimination; myelination of white matter fibers ...) and the brain changes are particularly intense during the last weeks of pregnancy and the first postnatal months. This stage is particularly vulnerable to any disturbance of the biological and nutritional balance [14].

\subsection{Postnatal Period}

1) The theory of Piaget (1896-1980)

Piaget, one of the first founders of developmental psychology, proposed 4 stages of cognitive development in children: Sensorimotor stage (0 - 2 years) (Permanence of the object, mental representation, delayed imitation), the stage preoperative (2 - 7 years) (Language, drawing, intuitive reasoning), concrete operating stage: classification and serialization (7 - $11-12$ years) and formal operating stage: reasoning (12 years - adult). However, the study will focus mainly on the first two stages: sensorimotor stage and the preoperative stage.

The sensorimotor period ( 0 to 2 years): During this phase, the baby mainly uses his senses and his motor skills to explore and adapt to his environment. The role of the environment, and in particular of the parents, is therefore crucial, according to Donald Woods Winnicott "A child alone without his environment, it does not exist", it is essentially the mother-baby couple based on the interactions between needs and responses. Bowlby in his writings says that even feeding a child is not enough to ensure emotional security, continuous relationships with 
stable figures are important for a child's psychological development. The child is therefore an active agent in interactions with his environment and the emotional bond woven with the parents now becomes the main determinant of the quality of development [15]. The infant is thus both stimulated and reassured. It is the quality of the interaction with the environment that will, in large part, determine the future possibilities for the expression of these skills.

Winnicott also mentions a period which extends from 0 to 5 months, corresponding to "the primitive psychic phase", during which the child must be fed, cleaned and where the role of the caregiver is crucial. This is the "primary maternal concern" a state of empathy of the mother who identifies more or less consciously with her newborn to know what he needs, how to carry it ("holding") and how to treat it ("handling") [16].

At the age of 9 months, the baby is sitting without support, able to pick up toys, transfer them from hand to hand and able to pick up very small objects between the thumb and the first finger, babbling consonants and vowels and modulates the height and volume. He is able to understand his needs for eating, drinking and the need for diaper changes. This period was dominated by considerable progress in sensorimotor action or "sensorimotor intelligence" without thought or representation. According to Piaget, this is the stage of the permanence of the object, mental representation, delayed imitation. Language, admittedly limited in space and time, is based on action and perception. The child is in a state of initial indifferentiation with the environment, but he will gradually build the notion of object, during various adaptive interactions between the reflexes that the child has at birth and the situations of the environment to which he will be confronted.

Infant-juvenile period: 2 to 6 years: This is the stage of access to Representative Intelligence: to attribute a kind of mental presence to an absent object. The differentiation of a signifier and a signified. The child then becomes capable of representing an absent signified (representation of the object) by means of a present signifier (the word, symbolic play, drawing) and by using signs and symbols = semiotization. Passage also from sensorimotor schemas to conceptual schemas which manifests itself in the simultaneous appearance of deferred imitation behaviors, symbolic games, drawing, mental images (internalized imitation) with an explosion of language around the age of 3 years. The child thus gains in independence and insurance.

At the age of 4, the neurological system becomes quite complex. The child can ask more complex questions: when, why and how, understands the feelings of others, better accepts the limits imposed by adults, manages frustration and opposites better, and is able to follow a set of instructions more complex thereafter.

2) The epigenetic theory of Wallon

It is a concrete multidimensional approach. According to Walloon, the child is already a social being and actively participates in its development, his theory offers 6 stages: 
- The stage of motor impulsivity (from birth to 2 months): in this stage expulsion from the maternal body forces the child to sketch out his relationships with the outside world, to multiply, intensify and complicate his motor reactions. During this stage, physiological autonomy increases (breathing) and food function becomes more complex. The child will then experience the sufferings of waiting or deprivation, which are manifested externally by spasms, tenses and cries [17].

- The emotional stage (from 2 to 3 months up to $8-12$ months): this stage peaks around the middle of the first year. During this stage and around 3 months the child already knows how to send to those around him, and particularly to his mother, smiles and signs of contentment which are already an emotional bond. At the level of the mother-child relationship, it is a transition from a simply physiological symbiosis to an emotional symbiosis. Throughout this stage, multiply and refine exploratory reactions which prepare the next stage.

- The sensorimotor and projective stages (between the end of the $1^{\text {st }}$ year and the end of the $3^{\text {rd }}$ year): this period is generally characterized by a centrifugal reversal of psychic orientation, especially in the $1^{\text {st }}$ stage (sensorimotor stage until around 18 months). The child, at the start of the second year, is almost completely turned towards the outside world. Investigation and exploration of objects and the environment are becoming dominant. The practical and cognitive conquest of the environment takes place along 3 main axes; manipulation, locomotion and denomination. From the middle of the second year, the child enters the projective stage: it is the establishment of a representative intelligence which takes its source in the game of attitudes and it requires the use of language to refine fully [17].

- The stage of personalism (between 3 and 6 years old): in this stage the self-arises by opposing (personality crisis) and an attitude of refusal becomes usual as if the only concern of the child was to safeguard the newly discovered autonomy of his person. The perception of the presence of others gives rise to inhibition reactions, to manifestations of shyness accompanied by clumsiness. Towards 5 - 6 years especially, the personalism of the child results in a new form of differentiated relations with others; this is the rise of an imitation of a model (favorite character and often jealous). Self-care also involves an essential reference to others and the child can only please him if he feels he can please others. Thus personable reactions invade the child's behavior and the aggressive or arrogant tone becomes conciliatory or seductive. And the last two categorial stages (6 - 11 years) where there is intellectual predominance, differentiation between objective and subjective and the stage of puberty where the demands of personality come to the fore. Walloon therefore has a more general approach, more global than that of Piaget, because he was interested in the construction of the personality encompassing social, intellectual and emotional dimensions as affectivity or intelligence. 


\section{Domains of Development}

Early childhood development takes place in several interrelated areas: physical, cognitive, language and socio-emotional. Each of these areas influences and depends on the others. To distinguish, during this development, two different but complementary phenomena: physiological growth which is defined as a change in size and weight gain and psychological development which is characterized by the evolution of skills and functions. One organ in particular plays an essential role: the brain.

\subsection{Brain Development}

Brain growth is the consequence of the increase in the volume occupied by cells (neurogenesis and myelination), and the functional maturation of cells and their connections (synaptogenesis). One of the characteristics of the cerebral architecture of the child's brain compared to the adult brain, is the notion of neuronal and synaptic redundancy. It is important to recognize that the nervous system continues to reshape and change not only in early development, but throughout life in response to environmental influences as well as genetically programmed events [18]. The majority of brain growth takes place in the first year and the vast majority before 4 years. At birth, the brain has already reached $25 \%$ of its adult mass, $66 \%$ at 1 year and $90 \%$ at 3 years [19]. Thus the relationships and bonds that we weave from birth through interactions, experiences, stimuli, influence the development of nerve connections.

The priority role of parent-child interactions should be emphasized, with parents being the primary stimulants in early childhood.

\subsection{Postural, Sensory and Motor Development}

All the senses are very developed from birth except that of sight, but very quickly the vision of the child improves day by day. Motor skills are dependent on two systems: The lower or cortico-spinal system whose maturation is early and ascending and is expressed during the third trimester of pregnancy and, the upper or cortico-spinal system which begins at birth and whose maturation is later and descending.

Indeed, examination of the newborn reveals the presence of so-called archaic or primary motor reflexes, spontaneous movements with hypertonia of the limbs and axial hypotonia. The development takes place according to a cephalo-caudal progression and, is marked by the progressive disappearance of reflex motor skills around the age of 4 months, the relaxation of the passive tone of the limbs and the progressive installation of a controlled motor skills more and more precise and quick between 5 months and 5 years. These motor acquisitions have an important functional and adaptive value and are the sign of a good maturation and a good functioning of the upper cortico-spinal system [20] [21]. Motor acquisitions are dependent more to brain maturation, perceptual and cognitive capacities and also experience [22]. The first is little influenced by intelligence 
and the environment and the acquisition sequences are little affected by specific sensory impairments (blindness, deafness). Fine motor skills, which essentially concern handling skills, are dependent, in addition to brain maturation, on the child's visual and cognitive perceptual capacities.

\subsection{Cognitive Development}

The word cognition comes from the Latin "cognocere" (to know). Cognition is defined as the set of processes that allow the processing of information and the constitution of knowledge. Cognitive development (of knowledge), refers to thinking, reasoning and intelligence. Cognition (or thinking) has several broad categories: perception, memory, learning, language, intelligence, reasoning, attention processes and decision making. The child acquires knowledge during the 0 to 5 year periods. Encouraged and stimulated by those around him, the child gradually explores, discovers, experiments and builds knowledge of his environment.

The first to propose a model of intellectual development for children is Piaget (1896-1980) who, according to constructivist theory, emphasizes the effect of the environment and its interaction with cerebral maturation. It describes 4 stages of intelligence development: Sensorimotor stage (0 - 2 years): Permanence of the object, mental representation, delayed imitation; Preoperative stage (2 - 7 years): Language, drawing, intuitive reasoning; Concrete operations stage (7 - 11 years old): Storage of measurements, logic of classes and operations; Formal operation stage (from 11 - 12 years old): Hypotheticodeductive and combinatorial reasoning.

\subsection{Psychoaffective Development}

Psycho-emotional development refers to the bonds that the child establishes with his parents and to the expression of his feelings and emotions which he learns to manage little by little.

This area of development is very important based on the parent-child relationship. By the signals, the responses, the reactions on the part of the child and the parents, there is established an "interactive synchrony" and a reciprocity in the relationship. Parents have a primary role in establishing the bonding relationship through their attitude, behaviors and how they respond [23].

This reciprocal affective relationship which is gradually built up between the child and the stable figures, will have an important influence on personal security, confidence, autonomy, socialization, in short on the development of the personality of the child.

\subsection{Social Development}

As the family is the first place of socialization, the parents will influence the development of the child's social skills. They can, for example, teach him strategies to get in touch with others, to develop empathy, etc. The relationship developed 
with the parents gives him the security he needs to reach out to others and interact with siblings, friends or other children.

The cognitive, affective and social spheres influence each other as always. For example, at a cognitive level, being around other children means that they no longer have to take into account their own point of view, but to take into account that of others. While on a social level, playing with others allows him to put into action different skills that stimulate the cognitive (solving problems, imagining games, developing his sense of humor). The more he develops these skills, the more enriching his contacts with others. Furthermore, at the emotional level, by being in contact with others, he develops the management of his emotions. Thus, we find that the more harmonious his emotional development, the more pleasant he has contact with others.

Also, several scientific studies have shown [24] that a social and psychological development of the child, without oppression and without stress, also influence his physical growth, Likewise, an adequate psycho-affective development of the child and an interaction with his environment, will promote its development. In addition, the environmental factors which intervene during early childhood, can have a decisive impact on the development of the individual, namely consequences on biological and social functions and on behavior throughout life [25] [26].

\section{Development or Neuro-Developmental Disorders}

"Developmental disorders" means any situation of maladjustment, any difficulty or problem which has the characteristic of presenting disturbances in the acquisition, assimilation or application of specific skills or sets of information. Those disorders generally appear during early childhood and are characterized by developmental delay, result in cognitive, behavioral and sensorimotor impairments leading, among other things, to dysfunction of attention, memory, perception, language, problem solving or social interaction. However, it often takes several years between the appearance of the first symptoms and their detection.

Developmental delay may relate to a single aspect of development (language delay or isolated motor delay, etc.) or in different aspects of development (overall developmental delay) [27].

Currently, the AAP [28] specifies that Developmental delay: if and only if the functional skills do not appear at the expected age, but the usual sequence of appearance is respected. The delay can be global or dissociated. Developmental disorder: is identifiable when an abnormality of the neurological or developmental examination is associated with a functional limitation, in this case, the acquisitions are not delayed, but deviant, not resembling the usual sequence of maturation of a function [29].

Several epidemiological studies [30] [31] show that approximately $10 \%$ to $15 \%$ of children between 3 and 5 years old, present problems in behavior or in the sphere of effects, $50 \%$ of them they will continue to present these problems dur- 
ing the preteen years. In the U.S. alone, it is estimated that $9 \%$ of children younger than 36 months of age have a possible developmental problem [32], while $13.87 \%$ of children 3 to 17 years of age have a developmental disability [33].

Longitudinal studies [34] also make a link between early behavioral and emotional difficulties and adult psychopathology. These studies allow us to conclude that the quality of parent/child interactions is strongly associated with the severity and continuity of behavioral problems in young children.

Lavigne [31] note that dysfunctional or "inconsistent" parent/child interactions and a disadvantaged family and social environment are associated with maintaining behavioral difficulties between the ages of 2 and 5 years, the study by Ana Sancho Rossignol in 2005, shows the existence of links between dysfunctions in early parent/child interactions, behavioral problems and the presence of "preforms" of psychopathological organization in very young children [35].

The model of psychopathology thus goes from a direct dyadic and causal mode, where psychopathology is the consequence of disorders of the motherchild relationship, to a sequential and systemic, family model, proceeding in stages, depending on the intensity risk and resilience factors, and on a model of genetic susceptibility influenced by the environment [36].

Global developmental delay and intellectual disability affect around $3 \%$ of the pediatric population [37] [38] [39].

One in 150 newborns are affected by an autism spectrum disorder; 1 to $2 \%$ of the population has an intellectual disability, the leading cause of disability in children; $5 \%$ to $10 \%$ of children, all "DYS" disorders combined, including $5 \%$ by written language disorders, presence of comorbidity in almost $40 \%$, (several types of disorder), among children with one or more "DYS": $1 \%$ have a severe form; $2 \%$ to $5 \%$ : HPI (high intellectual potential) recognized as a disability according to the minimum intellectual quotient threshold used; $10 \%$ to $15 \%$ of children with simple learning delay, the causes of which can take root in the child's environment.

The cause of developmental delays is not always identified despite a detailed etiological assessment in $40 \%$ to $50 \%$ of cases. The dynamics of development are important to clarify because schematically we contrast the pathologies fixed to progressive pathologies (where we find the concepts of stagnation or regression in the development of the child).

In the face of any concern in this area, instead of just waiting and seeing, it is recommended to use standardized screening tools. These disorders can be mild and easy to manage with educational and behavioral interventions, or they can be more severe and children affected by them are likely to require more assistance.

\section{Classification of Disorders}

Early childhood development disorders from 0 to 6 years old can be classified according to whether they are more related to: The influence of the environment 
(post-traumatic stress disorder and adjustment disorder); A biological vulnerability of the child (disorder of the regulation or disorder of the relation and the communication), The disorder also takes very different forms according to the reality of the lived event, and what it is about its construction or its reconstruction by the child himself, or that they result from a failing relational environment (affect disorder).

Defining and classifying the various disorders of early childhood development is referring to the two main international classifications:

ICD 10 and soon ICD 11 will focus, during early childhood, on mental, behavioral and neurodevelopmental disorders and are characterized by clinically significant disturbances of cognition, emotional regulation or behavior of an individual, reflecting a dysfunction of the psychological, biological or developmental processes underlying mental and behavioral functioning. These disturbances are generally associated with distress or impaired personal, family, social, educational, professional or other functioning.

Our discussion will focus on the recent version of DSM-5 due to the organization of diagnostic categories for infants and infants who have undergone significant changes in the DSM- 5 classification; the diagnoses thus are registered under the classification of neurodevelopmental disorders.

\section{Description of the Different Early Childhood Development According to DSM5}

Developmental disorders include cerebral palsy, developmental delay, mental handicap, primary language disorder or dysphasia, autism spectrum disorder (ASD), attention deficit disorder with/without and hyperactivity (ADD/ADHD), learning disabilities, coordination acquisition disorder (CAD) as well as genetic and chromosomal abnormalities.

\subsection{Neuro-Developmental Disorders}

Intellectual deficit (intellectual developmental disorder): Presence of deficits in intellectual functions such as reasoning, problem solving, planning, abstract thinking, judgment, academic and experiential learning, and deficits in adaptive functioning that result in disability for individual to meet the developmental and socio-cultural requirements of personal independence and social responsibility.

Specific learning disabilities: Look for difficulties in at least one of these three areas: transcription, writing or arithmetic.

Motor disorders: These disorders fall into three types. Developmental coordination disorder (i.e. delay in crawling or walking, escaping things or poor performance in sports; Disorder of stereotypical movements; Tic disorder and; Other specified tics or Unspecified tics.

Communication problems: There are four types of communication disorders: Language disorder, which is a developmental disturbance of vocabulary resulting in an inability to make sentences appropriate for the subject's age; Phonation 
(speech and articulation) disorder; Verbal fluency appearing in childhood (stuttering); Social Communication Disorder (pragmatic); Unspecified communication disorder, diagnosis made by a clinician who does not want to specify how the disorder does not meet all the criteria of one of the four previous diagnoses.

Autism spectrum disorders: Persistent deficits in communication and social interactions observed in various contexts, either in the current period or in the past: Deficits in social or emotional reciprocity; Deficits in nonverbal communication behaviors used during social interactions; Deficits in developing, maintaining and understanding relationships; Restricted and repetitive nature of the behaviors, Extremely restricted and fixed interests, abnormal either in their intensity, or in their aim Hyper or hypo-reactivity to sensory stimulations or unusual interest for the sensory aspects of the environment [40].

Attention deficit disorder with or without ADHD hyperactivity: Persistent mode of inattention and/or hyperactivity-impulsivity that interferes with functioning or development, characterized by Inattention: Six (or more) symptoms persist for at least 6 months, to a degree that does not correspond to the level development and which has a direct negative impact on social and school/ professional activities (Makes a lot of careless mistakes; Difficulty sustaining attention at work or in games; Not listening; Difficulty following instructions; Difficulty organizing work and activities; Dislikes or avoids tasks that require sustained mental effort; Losing business; Easily distracted; Frequent forgetfulness in everyday life).

Hyperactivity and Impulsivity: Six (or more of the following nine symptoms have persisted for at least 6 months (Wiggles hands or feet often, wiggles in chair; Difficulty sitting; Short or climbing everywhere; Difficulty playing quietly; Often "on the breach" or "mounted on springs"; Talks too much; Rushes to answer questions; Difficulty waiting his turn; Interrupts others or imposes himself).

These inattentiveness or hyperactivity-impulsivity symptoms were present before the age of 12, and they are present in two different contexts (eg school and home). In addition, Autism Spectrum Disorders are no longer considered to be incompatible with a diagnosis of ADHD.

\subsection{Other Development Disorders}

Oppositional Provocation Disorder: Angered/irritable mood, quarrelsome/provocative behavior, or a vindictive spirit persisting for at least 6 months during which at least 4 (or more) symptoms of the following categories are present, and manifesting itself during interactions with at least one subject external to the siblings.

Conduct Disorder: A set of repetitive and persistent behaviors in which the fundamental rights of others or the social norms and rules corresponding to the subject's age are violated, as evidenced by the presence of at least three of the 15 criteria during in the last 12 months, and at least one of these criteria in the last 6 months (Assault against people and animals, Destruction of material goods, 
Fraud or theft, Serious violations of established rules, etc.).

Anxiety Disorders: The anxiety disorders section in the DSM-V includes 10 disorders: panic disorder, agoraphobia, generalized anxiety, specific phobia, social anxiety disorder also called social phobia, generalized anxiety, anxiety disorder caused by a general medical condition, substance-induced anxiety disorder in which anxiety symptoms are the prominent feature of the clinical picture, and finally separation anxiety.

Trauma or stress disorders: In this category, the six disorders in the DSM-5 are caused by exposure to a natural or man-made disaster or to a major life stressor. for example the experience of physical or moral abuse (Reactional Attachment Disorder; Disinhibition Disorder of Social Contact; Post Traumatic Stress Disorder; Acute Stress Disorder; Adjustment Disorders; Other Related Disorder trauma or stressors, specified; Disorder of trauma or stressors, unspecified).

Eating behavior and food intake disorders: These disorders are characterized by a disturbance in food function. And it is necessary for all, if necessary, to specify if: In remission, or In partial remission, In complete remission, and the level of severity: Mild, Medium, Severe, Extreme. Anorexia nervosa, Bulimia nervosa, Binge-eating disorder, PICA, Merycism (Rumination disorder), Restriction or avoidance of food intake disorder, Other eating or food intake disorder, specified, Eating or food intake disorder, unspecified.

Sphincterian Control Disorders: These are disorders of elimination functions that are caused by physiological or psychological factors (Enuresis Disorder which is the inability to control the bladder, and it must be specified whether it is Exclusively nocturnal, Exclusively diurnal or nocturnal and diurnal; Encopresis Disorder which is the inability to maintain intestinal control and it must be specified whether it is With or Without constipation and overflow incontinence or Without constipation and overflow incontinence; The Other specified sphincter control disorder; Unspecified sphincter control disorder, this disorder presents with urinary symptoms or with fecal symptoms, such diagnosis is made in the absence of all of the criteria for the elimination disorders previously mentioned and generally in a situation of incomplete information.

Sleep-wake alternation disorders: These disorders involve a disturbance in the quality, schedule or duration of sleep, a disturbance which results in an alteration in daytime functioning and causes mental distress. In all cases, you must first specify whether the disorder is Episodic (lasting at least one month but less than three months) or Persistent (lasting more than three months), or Recurrent (at least two episodes in one year), then if it is Acute (having lasted less than a month), Subacute (having lasted more than one month and less than three months) or Persistent, (having lasted more than three months) and finally if its level of severity is Mild (difficulty in maintaining daytime alertness one or two days a week) Medium (difficulty in maintaining daytime alertness 3 to 4 days a week) or Severe (difficulty in maintaining daytime alertness 5 to 7 days a week). 
We find: The Insomnia Trouble; Hyper Drowsiness Disorder; Narcolepsy which is characterized by sudden attacks of sleep, generally with loss of muscle tone; Sleep disorders related to breathing; Disorders of the sleep-wake pattern linked to the circadian rhythm. In these disorders, there is a disturbance of the circadian system leading either to insomnia or to excessive drowsiness; and Parasomnias, these disorders consist of unusual situations of behavior, experience or physiological events during the night.

Disruptive disorders, impulse control and conduct: we find the conditions involving problems of self-control of emotions and behaviors (Oppositional provocative disorder; Intermittent explosive disorder; Disorder conduct; Pyromania disorder; The Kleptomania Disorder; The other disruptive disorder, impulse control and behavior, specified; The disruptive disorder control impulses and unspecified behavior; The Personality disorder.

Neurocognitive Disorders: These disorders are characterized by changes in the structure of the brain and its functioning, which results in impaired learning, orientation, judgment, memory and intellectual functions. These disorders were formerly called dementia, delirium, amnesic disorder and other cognitive disorders.

\section{Support of Early Childhood Development Disorders (ECDD)}

Identifying difficulties early allows you to intervene without delay and to be more effective. Interventions via the ECDD, must target the many risks that children undergo early. These are reactive disorders, which are not yet registered in the child's psyche and which have not yet given rise to harmful relationship vicious circles. These situations most often, but not always, show great plasticity and a potential for reversibility at a time when the development of the brain is in its most intense phase "The plasticity of the brain compensates for certain deficiencies". And if the disorders are more serious, it is important to treat them early in life to prevent the child's development from being too much affected [41]. The earlier we intervene, in a favorable and sustained manner, the better the results. This is more effective than trying to remedy cumulative deficits later in life [42]. When the disorder results from a trauma, the intervention will be mainly environmental and will focus on the practical consequences of the trauma.

In the case of an affective disorder, therapeutic interventions must above all focus on the quality of the parent/child relationship. On the other hand, when it is a regulatory disorder or a relationship and communication disorder, the interventions should be primarily educational in nature and relate, for example, to sensory integration or the child's motor skills.

In addition, the child is a developing being, so there are always difficulties in locating the value of symptomatic disorganization. In addition, the expression of the lesion changes with the development of the child. In the first year, signs and symptoms are to be looked for in motor function, in the following years in lan- 
guage, fine motor skills and behavior, at school age it is rather in learning disabilities.

In all cases, the objective will be an early detection of the delay to initiate appropriate care and minimize the long-term consequences.

\section{Development Screening and Diagnostic Tools}

To identify people with ECDD, a comprehensive assessment should include historical information such as a pregnancy, labor, delivery, first neonatal treatment, history of development, and communication milestones and motor skills.

The medical history should include screening for sensory deficits (hearing or visual impairments, for example), as well as a discussion of other medical conditions and specific signs and symptoms. History and physical examination may assist in the search for known or associated etiological conditions.

The delay will be confirmed by the use of calibrated tests, the passing of which will be carried out by the appropriate professional (e.g. passing of a psychometric test by a psychologist or neuropsychologist, taking of motor tests by a psychomotrician, passing of language tests by a speech therapist).

However, screening requires neuropsychological evaluation by qualified health professionals experienced in the use of the guidelines using age-appropriate tools and scales involved in the diagnosis of the disorder early childhood development (ECDD) to confirm or not the diagnosis such as for:

Infant: ADBB, Massy Campbell, STAI, PPQ, IDI, IDE.

ADBB [43]: Observation of relational withdrawal of the baby, child from 2 to 24 months, it contains 8 Items: Facial expression; Eye contact; General level of activity; Self-stimulation gestures; Vocalizations; Briskness of response to stimulation; Relationship to the observer; Attractiveness to the observer.

Massy Campbell contains 20 items: mood in the past 7 days, score 0-60; Depression thresholds are possible between 16-22, and likely if $>23$.

STAI (State-Trait Anxiety Inventory): 20 items (0 to 4 points) on anxiety, anxiety threshold if $>40$. Anxiety-state scale (at this precise moment); Anxiety-trait scale (in general).

PPQ (Perinatal Post-traumatic stress disorder Questionnaire): Memories of hospitalization, birth and stay in neonatology intruding into the maternal psyche and active avoidance mechanisms 6 months after birth, duration more than a month, it contains 14 items ( 0 to 4 points), post-traumatic stress threshold greater than 19 .

IDI (Infant Development Inventory): The Infant Development Inventory [44] was developed by Ireton to cover the period from birth to 21 months of age. Parents describe their infant in terms of current behaviors using an Infant Development Chart, describing patterns of behavior expected across the five domains of fine motor, gross motor, social, self-help and language. The IDI is a descriptive tool which health professionals ask concerned caregivers to complete at-risk infants are referred for subsequent assessment. 


\section{Preschool: IDE, CBCL, M-CHAT, ASQ-SE}

CDI (Child Development Inventory) 15 months to 5 years and 11 months: IDE is a simple and fairly rapid tool, designed to identify and assess the development problems of young children in different development areas and thus determine the age of Development $(\mathrm{AD})$ versus chronological age $(\mathrm{AC})$. This momentary estimate of development will be supplemented by successive evaluations which will make it possible to assess the dynamics of development [45].

CBCL (Child Behavior Check List): 1.5 - 5 years; Parental question of 100 items (score 0.1 or 2 ) grouped into, it contains 7 scales: (I. Withdrawn, II. Somatic Complaints, III. Anxious/Depressed, IV. Social Problems, V. Thought Problems, VI. Attention Problems, VII. Delinquent Behavior, VIII. Aggressive Behavior, and IX. Sexual Problems [46].

M-CHAT (Modified Checklist for Autism in Toddlers): from 16 to 30 months; it consists of 23 items, including 6 that discriminate if "NO"; item 2: Interest in other children; Item 7: Proto-declarative score (point the finger to indicate an interest in something); Item 9: Bring objects to parents; Item 13: Imitation; Item 14: Response of the child to his first name when he is called; Item 15: Ability to follow the adult's score [47], and other test for Autism spectrum disorder as: ADOS, ADI-R, CARS.

ASQ: SE (Ages and Stages Questionnaire: Social-Emotional). The ASQ: SE is a brief parent-or teacher-reported instrument designed to assist in identifying developmental delays in children aged six to 60 months. There are three response options (rarely or never, sometimes, most of the time) for each item, which are scored zero, five, and ten with a possible additional five points if this specific behavior worries the informant. A total difficulty score is calculated by adding the points from all the items and the items related to expressed concerns [48].

\section{School: SDQ, SCQ}

Self-description questionnaire (SDQ): 2 - 4 years and 4 - 17 years: Parental questionnaire, self questionnaire, or Teacher questionnaire, it contains 25 items rated from 0 to 2: Emotional disorders; Behavior disorder; Hyperactivity; Relationship disorder [49] [50].

Social Communication Questionnaire (SCQ): Parental questionnaire for ASD $<10$ minutes, it contains 40 "Yes or No" items, for children over 4 years old, with a mental age over 2 years. SCQ is fast and inexpensive for routine screening for ASD [51].

Other supplementary examinations: Electroencephalograms (EEG): In case of convulsive disorder or associated signs leading to a degenerative condition; Potential Hearing Events (PEA): A hearing evoked potential assessment and a complete speech and language assessment should always be performed in any child with speech delays; Genetic counseling and test: It is important to provide genetic counseling after a diagnosis of ECDD in order to provide parents with information on the risks of recurrence in the following children. Conventional methods of genetic testing to identify conditions associated with ECDD can in- 
clude karyotype and/or fluorescence in situ hybridization (FISH).

In addition, due to the heterogeneity of ECDD, the multiple etiologies, and the questionable clinical validity of extensive screening tests for all children with ECDD, additional evidence is required before genetic testing of this population becomes the norm of care.

\section{Remediation}

According to the National Institute of Child Health and Human Development, there is currently no single, definitive treatment for ECDD remediation. People with ECDD have a wide range of behaviors and abilities, so that no approach is as effective for everyone, and not everyone involved in outcome studies has benefited to the same extent.

In addition, people with ECDD may need new and/or multiple sets of care or changes in the frequency and duration of existing services. These changes are usually based on a review due to the severity of the current situation, as well as changes related to growth and development, caregivers, the environment, or functional requirements. We know that remedial actions will be all the more effective in preventing school failure because they will have been implemented as early as possible, during the most favorable period of development.

The main objectives in the management of TDPE are to minimize the main characteristics and associated deficits, to maximize functional independence and quality of life and to relieve family distress [52], but also to include services such as, but not limited to:

Pharmacological therapy: Consensus on recommended guidelines for the use of drugs in the management of TDPE has not been reached. Currently, the U.S. Food and Drug Administration has not approved any drugs specifically for the treatment of ECDD. However, medications can be used to treat some of the symptoms associated with ASD (for example, aggression, hyperactivity, inattention, depression, anxiety).

Physiotherapy: It is a treatment prescribed by a doctor for physical disabilities or impairments resulting from illness, injury, birth defect and/or previous therapeutic intervention. Characteristics of ECDD may include delays in the achievement and development of motor skills and sensorimotor adaptation, unusual postures and movements, poor balance reactions, decreased muscle performance and the extent of mobility, as well as a general lack of physical condition. Associated conditions may include, but are not limited to: hypotonia, limb apraxia, and joint laxity.

Occupational Therapy: Occupational therapy practitioners work with people with ECDD to help them succeed in participation and adjustment in school, home and social environments.

Speech therapy: Help treat specific speech and language deficits, as well as related eating disorders. Speech therapy services should help the communicative partner (teacher, parent, caregiver, peer and brother) to provide support and use 
of specific teaching strategies to enhance active participation in natural learning environments.

Psychiatric services: Direct or advisory services are provided by a doctor specializing in psychiatry, responsible for diagnosing ECDD and/or diagnosing and treating concomitant psychiatric disorders presented by the subject.

Psychological services: A psychologist treats the psychological disorders associated with ECDD.

Neuropsychological Assessment (NPA): The NPA consists of the administration of a series of standardized tests of different mental functions and the interpretation of the results in order to allow the deduction of brain function. There are too few peer-reviewed publications to support the standard use of NPA in people with ECDD. However, NPA can be useful in assessing specific neurological conditions present in a person suspected of having ECDD.

Applied Behavior Analysis (ABA) and other methodologies to promote learning: Methodologies to promote learning are believed to improve communication, teach social skills and reduce inappropriate behavior. These methodologies are based on several model programs, including behavioral, structured and/or developmental education.

Among the many methodologies available for the remediation of early childhood developmental disorders, $\mathrm{ABA}$ : is undoubtedly the most studied treatment modality in the field. It is generally accepted that ABA is the process of applying interventions based on the principles of learning (positive reinforcement, for example) derived from research in experimental psychology to systematically change behavior. It can also be used to teach new skills and demonstrate that the interventions used are responsible for observable improvements in behavior.

$\mathrm{ABA}$ methods would be used to replace inappropriate and interfering behaviors with more desirable adaptive behaviors and to refine the conditions under which these behaviors occur. In addition, it is believed that ABA teaches new skills through implicit instruction and repetition, generalizing behaviors in new environments or situations and maintaining learned behaviors. For example, clear instructions with assistance (demonstration, incentive, for example) are given to the person. When the person gives the correct answer, the instructor gives positive reinforcement.

Some methodologies to promote learning have also emerged and, although they are not considered behavioral, they share common elements with behavioral methodologies. For example, the TEACCH (Treatment and Education of Children with Autism and Related Communication Disorders) Structured Teaching Model uses many forms of visual aids, such as picture calendars, to help people with ECDD.

Another modality commonly used with individuals is the developmental approach. Examples of a developmental approach include, but are not limited to, the Denver model (which emphasizes intensive teaching and the development of social communicative skills) and/or the time development model based on indi- 
vidual difference, the relationship focuses on building emotional reciprocity). Despite the common use of such methodologies to promote learning, most have not been empirically validated.

Alternative therapies and complementary medicine or other therapy: Parents and/or caregivers sometimes turn to alternative therapies, complementary drugs and/or therapies not traditionally used in the management of ECD disorders, note food supplements; Immunoglobulins; Secretin in the treatment of ECD disorder is based on the theory that a link exists between gastrointestinal disorders and brain dysfunction; chelation therapy: Advocates of chelation therapy believe that ASD is caused by childhood exposure to environmentally toxic substances, mainly metals (especially mercury in vaccines) and minerals [53], therefore, there are no data on the efficacy of chelation therapy for the treatment of ASD.

The International Child Development Steering Committee (ICDSC) [54] defined the components of good integrated ECDD interventions such as: Integration of health, nutrition, education, socio-economic development and protection; Cooperation between public authorities and civil society; Focus on young disadvantaged children; The involvement of parents and families alongside teachers and other caregivers; An amalgam of traditional practices and science-based approaches; Programs of sufficient intensity, duration and quality experienced by the caregiver in contact with the baby and his family.

The help that must be given to families in suffering in the health service in Morocco: Creation of a space of trust and discussion with the family so that they feel safe enough to talk about what concerns them and them touch; Listening to them about their emotions, their feelings, their difficulties, their doubts, their suffering, possibly more ambivalent feelings towards the baby is very therapeutic support in itself; The observation of the baby or the examination of the baby according to the Brazelton method [55] (our team working on developing many researches in different neuropsychologist scales), allows the caregiver to focus on the parents and to focus on the baby and its primitive experiences. This can serve as a medium and allow some parents, who are more suspicious or in denial, to feel less threatened, to relax and to give themselves up a little more.

\section{Conclusions}

Early childhood is of crucial importance in relation to child development. Several research results reported in the literature indicate considerable changes at all levels of child development. These changes are constantly subject to various sources of influence, coming from his environment or inherent in himself and his type of evolution and therefore, subject to change. However, in order to guarantee good development for each child, early identification and treatment must be established. Several situations can be modified in this way and others are treated and resolved, others are also dealt with so that the harmful consequences are minimized and the child arrives at the best possible development. 
As a result, screening, diagnosis, care and support for the child are based on good interaction between care providers, making sure to give families a special place throughout the process and, ensuring a suitable orientation taking into account the economic and geographic reality of families. Several research studies show that high quality integrated programs are needed globally to ensure that all children reach their full potential and thrive.

\section{Conflicts of Interest}

The authors declare no conflicts of interest regarding the publication of this paper.

\section{References}

[1] Center on the Developing Child at Harvard University (2010) The Foundations of Lifelong Health Are Built in Early Childhood.

http://www.developingchild.harvard.edu

[2] Bloch, H., Chemama, R., Dépret, É., et al. (2011) Grand Dictionnaire de Psychologie.

https://www.bibliotheques-clermontmetropole.eu/s/search.php?lookfor=\%22Larous se\%22\&type=publisher

[3] Britto, P., Yoshikawa, H. and Boller, K. (2011) Quality of Early Childhood Development Programs and Policies in Global Contexts: Rationale for Investment, Conceptual Framework and Implications for Equity. Social Policy Report, 25, 1-31. https://doi.org/10.1002/j.2379-3988.2011.tb00067.x

[4] World Health Organization (WHO) (2009) Early Child Development. Fact Sheet $332^{\circ} \mathrm{N}$. Geneva, Switzerland: WHO.

[5] Sameroff, A.J. and Fiese, B.H. (2000) Transactional Regulation: The Developmental Ecology of Early Intervention. In: Shonkoff, J.P. and Meisels, S.J., Eds., Handbook of Early Childhood Intervention, 2nd Edition, Cambridge University Press, Cambridge, UK, 135-159. https://doi.org/10.1017/CBO9780511529320.009

[6] Maurice Tubiana. VST-Vie sociale et Traitements 2006/3 (No. 91), 116-143. https://doi.org/10.3917/vst.091.0116

[7] Jagodowicz, J. (2012) Le développement précoce: quels indicateurs pour prévenir d'un trouble? Psychologie. Université René Descartes-Paris V, Français.

[8] Michel, M. (1985) Temperamental Differences in Infants and Young Children. The Journal of Nervous and Mental Disease, 173, 320.

[9] Piaget, J. (1952) The Origins of Intelligence in Children. W.W. Norton \& Co., New York. https://doi.org/10.1037/11494-000

[10] Kagan, J. and Havemann, E. (1976) Psychology: An Introduction. 3rd Edition, Harcourt Brace Jovanovich, New York.

[11] Irwin, L.G., Siddiqi, A. and Hertzman, C. (2007) The Total Environment Assessment Model of Early Child Development. WHO organisation mondiale de la santé.

[12] Littré, É. (1863-1877) Dictionnaire de la langue française, Volume 4. Paris, Librairie.

[13] OMS (2003) Consultation technique de l'OMS en vue d'élaborer une stratégie pour favoriser un développement optimal du fotus. Genève, 25-27 novembre 2003.

[14] Dubois, J., et al. (2011) Neurophysiologie clinique: Développement cérébral du nourrisson et imagerie par résonance magnétique. Neurophysiologie Cliniquel Clinical 
Neurophysiology, 42, 1-9. https://doi.org/10.1016/j.neucli.2011.08.001

[15] Bowlby, J. (1992, 1978) Attachement et perte: I L'attachement; II Séparation, angoisse et colère. III La perte, tristesse et séparation. PUF, Paris.

[16] Winnicott, D.W. (1941) The Observation of Infants in a Set Situation. International Journal of Psychoanalysis, 22, 229-249.

[17] Henri, W. (1959) Les étapes de la sociabilité chez l'enfant. In: Enfance, Psychologie et Education de P Enfance, tome 12, 309-323. https://doi.org/10.3406/enfan.1959.1446

[18] Nervous System (2000) For the Developing Environmental Health. Critical Periods. Perspectives, 108, 511-533.

[19] Papalia, D.E., Olds, S.W. and Feldman, R.D. (2010) Psychologie du développement humain. 71 .

[20] Gosselin, J. and Amiel-Tison, C. (2007) Évaluation neurologique de 0 à 6 ans. Presses de l'Hôpital Sainte-Justine, Montréal-Masson, Paris.

[21] Amiel-Tison, C. and Gosselin, J. (2010) Pathologie neurologique périnatale et ses conséquences. Masson, Paris. https://doi.org/10.1016/B978-2-294-70895-4.00018-9

[22] Blauw-Hospers, C.H. and Hadders-Algra, M. (2005) A Systematic Review of the Effects of Early Intervention on Motor Development. Developmental Medicine \& Child Neurology, No. 6, 421-432. https://doi.org/10.1017/S0012162205000824

[23] Eickmann, S.H., Lima, A.C.V., Guerra, M.Q., Lima, M.C., Lira, P.I.C., Huttly, S.R.A. and Ashworth, A. (2003) Improved Cognitive and Motor Development in a Community Based Intervention of Psychosocial Stimulation in Northeast Brazil. Developmental Medicine and Child Neurology, 45, 536-541. https://doi.org/10.1111/j.1469-8749.2003.tb00953.x

[24] Bigras, N., et al. (2009) Stress parental, soutien social, comportements de l'enfant et fréquentation des services de garde. Enfances, Familles, Générations, No. 10, 1-30. http://www.efg.inrs.ca https://doi.org/10.7202/037517ar

[25] Bhutta, A.T., Cleves, M.A., Casey, P.H., Cradock, M.M. and Anand, K.J.S. (2002) Cognitive and Behavioral Outcomes of School-Aged Children Who Were Born Preterm. JAMA: The Journal of the American Medical Association, 288, 728-737. https://doi.org/10.1001/jama.288.6.728

[26] Catherine, J. (2019) Une pédopsychiatrie clinique: Entre approche psychodynamique et neuroscientifique, réalités Pédiatriques.

[27] Shevell, M., et al. (2003) Practice Parameter: Evaluation of the Child with Global Developmental Delay. American Academy of Neurology, Minneapolis, MN.

[28] American Academy of Pediatrics (2006) Identifying Infants and Young Children with Developmental Disorders in the Medical Home: An Algorithm for Developmental Surveillance and Screening. Pediatrics, 118, 405-420.

https://doi.org/10.1542/peds.2006-1231

[29] Accardo, P.J., Accardo, J.A. and Capute, A.J. (2008) Chap. 1: A Neurodevelopmental Perspective on the Continuum of Developmental Disabilities. Capute \& Accardo's. Neurodevelopmental Disabilities in Infancy and Childhood (Vol. 1: Neurodevelopmental Diagnosis and Treatment). 3e Édition, Paul H. Brookes Publishing Co., Baltimore, MD.

[30] Campbell, S.B. (1995) Behavior Problems in Preschool Children: A Review of Recent Research. Journal of Child Psychology and Psychiatry, 36, 113-149. 
https://doi.org/10.1111/j.1469-7610.1995.tb01657.x

[31] Lavigne, J.V., Arend, R., Rosenbaum, D., Binns, H.J., Christoffel, K.K. and Gibbons, R.D. (1998) Psychiatric Disorders with Onset in the Preschool Years: I. Stability of Diagnoses. Journal of the American Academy of Child and Adolescent Psychiatry, 37, 1246-1254. https://doi.org/10.1097/00004583-199812000-00007

[32] American Academy of Pediatrics, Committee on Children with Disabilities (2001) Role of the Paediatrician in Family-Centered Early Intervention Services. Pediatrics, 107, 1155-1157. https://doi.org/10.1542/peds.107.5.1155

[33] Zablotsky, B., Black, L.I., Maenner, M.J., Schieve, L.A., Danielson, M.L., Bitsko, R.H., Blumberg, S.J., Kogan, M.D. and Boyle, C.A. (2019) Prevalence and Trends of Developmental Disabilities among Children in the US: 2009-2017. Pediatrics, 144, e20190811. https://doi.org/10.1542/peds.2019-0811

[34] Caspi, A., Moffitt, T.E., Newman, D. and Silva, P.A. (1996) Behavioral Observations at Age 3 Years Predict Adult Psychiatric Disorders Longitudinal Evidence From a Birth Cohort. Archives of General Psychiatry, 53, 1033-1039. https://doi.org/10.1001/archpsyc.1996.01830110071009

[35] Rossignol, A.S., et al. (2005) Psychiatrie de l'enfant. XLVIII, 157-198.

[36] Saïas, T., et al. (2010) Le développement précoce de l'enfant: Evolutions et révolutions. Devenir, 22, 175-185. https://doi.org/10.3917/dev.102.0175

[37] American Psychiatric Association (2015) Handicaps Intellectuels. In: Manuel diagnostique et statistique des troubles mentaux, 5e Edition, APA, Elsevier Masson SAS, Issy-les-Moulineaux, Paris.

[38] ACE (2015) America's Children and the Environment. 3rd Edition, Neurodevelopmental Disorders Health.

[39] Moeschler, J.B., Shevell, M. and Committee on Genetics (2014) Comprehensive Evaluation of the Child with Intellectual Disability or Global Developmental Delays. Pediatrics, 134, e903-e918. https://doi.org/10.1542/peds.2014-1839

[40] Mammad, K. and Ahami, A. (2018). Effect of a Serious Game Jestimule in Emotion Recognition of Moroccan Autistic Children. Journal of Educational, Health and Community Psychology, 7, 17-37. https://doi.org/10.12928/jehcp.v7i1.8429

[41] El-Kogali, S., Krafft, C., Abdelkhalek, T., Benkassmi, M., Chavez, M., Bassett, L. and Ejjanoui, F. (2015) Inequality of Opportunity in Early Childhood Development in Morocco over Time (Forthcoming). World Bank Policy Research Working Paper, Washington DC. https://doi.org/10.1596/1813-9450-7670

[42] Engle, P.L., Fernald, L.C.H., Alderman, H., Behrman, J.R., O’Gara, C., Yousafzai, A., de Mello, M.C., Hidrobo, M., Ulkuer, N., Ertem, I. and Iltus, S. (2011) Strategies for Reducing Inequalities and Improving Developmental Outcomes for Young Children in Low-Income and Middle-Income Countries. The Lancet, 378, 1339-1353. https://doi.org/10.1016/S0140-6736(11)60889-1

[43] Guedeney, A., Dumond, C., Grasso, F. and Starakis, N. (2004) Comportement de retrait relationnel du jeune enfant $\mathrm{Du}$ concept à l'outil diagnostique, médecine/sciences. https://doi.org/10.1051/medsci/200420111046

[44] Ireton, H. (1994) Infant Development Inventory. Behavior Science Systems Inc., Minneapolis, MN.

[45] Ireton, H. (1998) Child Development Inventory. Behavior Science Systems Inc., Minneapolis, MN.

[46] Achenbach, T.M. (1991) Manual for the Teacher's Report Form and 1991 Profile. Department of Psychiatry, University of Vermont, Burlington. 
[47] Robins, D.L., Fein, D., Barton, M.L. and Green, J.A. (2001) The Modified Checklist for Autism in Toddlers: An Initial Study Investigating the Early Detection of Autism and Pervasive Developmental Disorders. Journal of Autism and Developmental Disorders, 22, 375-394. https://doi.org/10.1037/t03999-000

[48] Squires, J., Bricker, D. and Twombly, E. (2002) The ASQ:SE User's Guide. Paul H. Brookes Publishing Co., New York.

[49] Leach, L.F., Henson, R., Odom, L.R. and Cagle, L.S. (2006) A Reliability Generalization Study of the Self-Description Questionnaire. Educational and Psychological Measurement, 66, 285-304. https://doi.org/10.1177/0013164405284030

[50] Marsh, H.W., Smith, I.D. and Barnes, J. (1983) Multitrait-Multimethod Analyses of the Self-Description Questionnaire: Student-Teacher Agreement on Multidimensional Ratings of Student Self-Concept. American Educational Research Journal, 20, 333-357. https://doi.org/10.3102/00028312020003333

[51] Rutter, M., Bailey, A. and Lord, C. (2003) The Social Communication Questionnaire: Manual. Western Psychological Services.

[52] Myers, S.M., Johnson, C.P. and The Council on Children with Disabilities (2007) Management of Children with Autism Spectrum Disorders. Pediatrics, 120, 1162-1182. https://doi.org/10.1542/peds.2007-2362

[53] Davis, T.N., et al. (2013) Chelation Treatment for Autism Spectrum Disorders: A Systematic Review. Research in Autism Spectrum Disorders, 7, 49-55. https://doi.org/10.1016/j.rasd.2012.06.005

[54] Irwin, L.G., Arjumand Siddiqi, R.N. and Hertzman, C. (2007) Le développement de la petite enfance: Un puissant égalisateur. Juin 2007 d'après le document Total Environment Assessment Model of Early Child Development (TEAM-ECD), pour la Commission des déterminants sociaux de la santé.

[55] Brazelton, B. and Cramer, B. (1991) Les premiers liens. Calmann-Lévy, Paris. 